\title{
Nickel and Manganese Interaction with Calcite
}

\author{
M. Zavarin \\ H. Doner
}

August 16, 1999

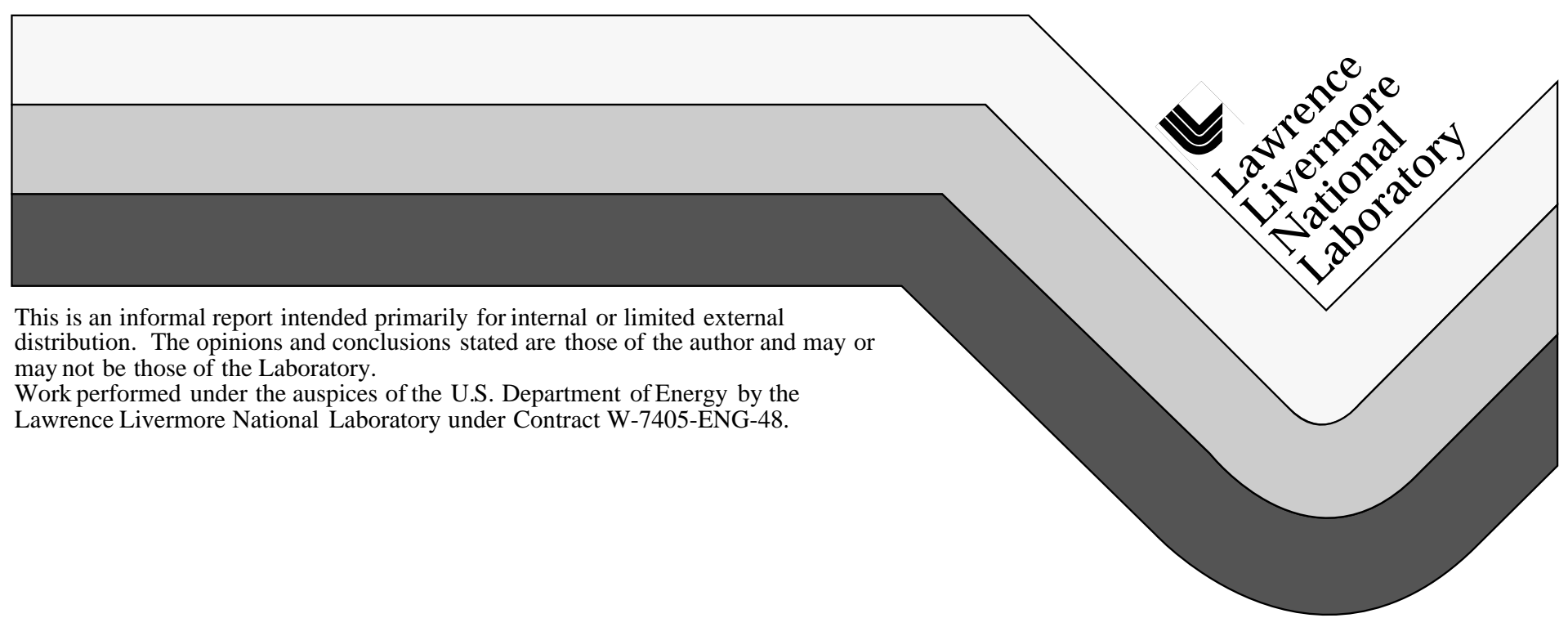




\section{DISCLAIMER}

This document was prepared as an account of work sponsored by an agency of the United States Government. Neither the United States Government nor the University of California nor any of their employees, makes any warranty, express or implied, or assumes any legal liability or responsibility for the accuracy, completeness, or usefulness of any information, apparatus, product, or process disclosed, or represents that its use would not infringe privately owned rights. Reference herein to any specific commercial product, process, or service by trade name, trademark, manufacturer, or otherwise, does not necessarily constitute or imply its endorsement, recommendation, or favoring by the United States Government or the University of California. The views and opinions of authors expressed herein do not necessarily state or reflect those of the United States Government or the University of California, and shall not be used for advertising or product endorsement purposes.

This report has been reproduced directly from the best available copy.

Available to DOE and DOE contractors from the Office of Scientific and Technical Information P.O. Box 62, Oak Ridge, TN 37831

Prices available from (423) 576-8401

Available to the public from the National Technical Information Service

U.S. Department of Commerce 5285 Port Royal Rd. Springfield, VA 22161 


\title{
Nickel and Manganese Interaction with Calcite
}

\author{
Mavrik Zavarin ${ }^{1}$ and Harvey E. Doner ${ }^{2}$ \\ ${ }^{1}$ Lawrence Livermore National Laboratory, Livermore, CA 94551 \\ ${ }^{2}$ University of California, Berkeley, CA 94720
}

\begin{abstract}
Introduction
Many divalent metal cations sorb to calcite surfaces and incorporate into calcite to varying degrees. Since calcite may sorb trace elements in the environment, the factors controlling metalcalcite interactions are critical to understanding element cycling. The interaction of divalent metal cations with calcite can be critical to toxic metal immobilization ${ }^{1}$, nutrient cycling, interpretation of past redox conditions ${ }^{2}$, tracing fluid flow $^{3}$, for example.
\end{abstract}

Sorption of $\mathrm{Ni}$ and $\mathrm{Mn}$ on calcite surfaces was studied by Zachara et al. ${ }^{4}$. At any particular $\mathrm{pH}$, the sorption of $\mathrm{Mn}$ on calcite was greater than Ni. This was attributed in part to the similarity of divalent $\mathrm{Mn}$ and $\mathrm{Ca}$ with respect to ion size. Although direct spectroscopic evidence was not available, sorption/desorption results suggested that Mn quickly forms a surface precipitate or solid solution while Ni forms a hydrated surface complex that may incorporate into calcite much more slowly via recrystallization. Because $\mathrm{Mn}$ (II) ionic radius is similar to that of $\mathrm{Ca}$ (II) (0.80 versus $1.0 \AA)$, and because $\mathrm{MnCO}_{3}$ has a structure similar to calcite, it is likely that $\mathrm{Mn}$ can substitute directly for $\mathrm{Ca}$ in the calcite structure. The ionic radius of $\mathrm{Ni}(\mathrm{II})$ is significantly smaller $(0.69 \AA)$ and $\mathrm{Ni}(\mathrm{OH})_{2}$ precipitation is likely to be favored in most systems. For $\mathrm{Ni}$, direct substitution for $\mathrm{Ca}$ is less likely or may require more significant calcite lattice deformation.

\section{Materials and Methods}

$\mathrm{Ni}$ and $\mathrm{Mn}$ sorption samples were prepared at beam line 4-3 at SSRL several hours prior to sample analysis. A range of solution metal concentrations were used $(5-100 \mathrm{ppm})$ to investigate concentration effects. Since XAS detection limits are high, samples required approximately $50 \mathrm{ppm}$ metal; thus, all sorption samples were supersaturated with respect to $\mathrm{Ni}(\mathrm{OH})_{2}$ or $\mathrm{MnCO}_{3}$. Coprecipitation samples were prepared using a $\mathrm{pH}$-stat set-up run at $0.03 \%$ and $0.25 \% \quad \mathrm{CO}_{2}$ and sodium chloride background electrolyte $\quad(\mathrm{I}=0.1) . \quad$ In coprecipitation samples, solutions were always undersaturated with respect to all known $\mathrm{Mn}$ or $\mathrm{Ni}$ minerals. Although this did not eliminate the possibility of trace metal precipitation (surface precipitates have been shown to form when solution concentrations are below the solubility of the particular mineral), it reduced the likelihood of mineral precipitation and was a better representation of solution metal concentrations in the environment.

\section{Results and Discussion}

\section{Ni(II) Sorption on Calcite}

Figure 1 contains EXAFS data for aqueous, sorbed, and coprecipitated Ni on calcite. For all sorption samples, no significant change in spectra occurred as a function of time during data collection. This indicated that, within the first several hours of Ni sorption, no significant restructuring occurred at the calcite surface. The EXAFS (and XANES) of all sorption samples were significantly different from aqueous $\mathrm{Ni}$ samples. This difference is indicative of innersphere $\mathrm{Ni}$ sorption or formation of $\mathrm{Ni}$ precipitates. The EXAFS FT data for sorbed $\mathrm{Ni}$ samples contained a second neighbor feature at $\sim 2.8 \AA$ (not corrected for phase shift). This feature was much smaller than that of $\mathrm{Ni}(\mathrm{OH})_{2}$, indicating that simple $\mathrm{Ni}(\mathrm{OH})_{2}$ formation did not occur.

The formation of surface multinuclear complexes with $\mathrm{Ni}$ was previously shown to occur in pyrophyllite sorption experiments ${ }^{5}$. Those experiments showed that multinuclear complexes formed well below the solubility product of $\mathrm{Ni}(\mathrm{OH})_{2}$ and that the relative $\mathrm{Ni}-\mathrm{Ni}$ coordination numbers increased with $\mathrm{Ni}$ loading. The increase in the second neighbor peak amplitude with increased loading was observed here as well. Formation of a $\mathrm{Ni}(\mathrm{OH})_{2}$-like surface precipitate or $(\mathrm{Ni}, \mathrm{Ca}) \mathrm{CO}_{3}$ near-surface solid solution is likely in our case.

Although sorption EXAFS data were noisy, fits were attempted for all samples. In all cases, 
second neighbor fits were the same or better when fitting with $\mathrm{Ni}$ and not $\mathrm{Ca}$. This suggests that $\mathrm{Ni}$ multinuclear complexes formed in these samples. In addition, $\sigma^{2}$ values for $\mathrm{Ca}$ fits were unreasonably low while those of $\mathrm{Ni}$ were similar to $\mathrm{Ni}(\mathrm{OH})_{2}$ fit results. The $\mathrm{Ni}-\mathrm{Ni}$ distance in sorption samples

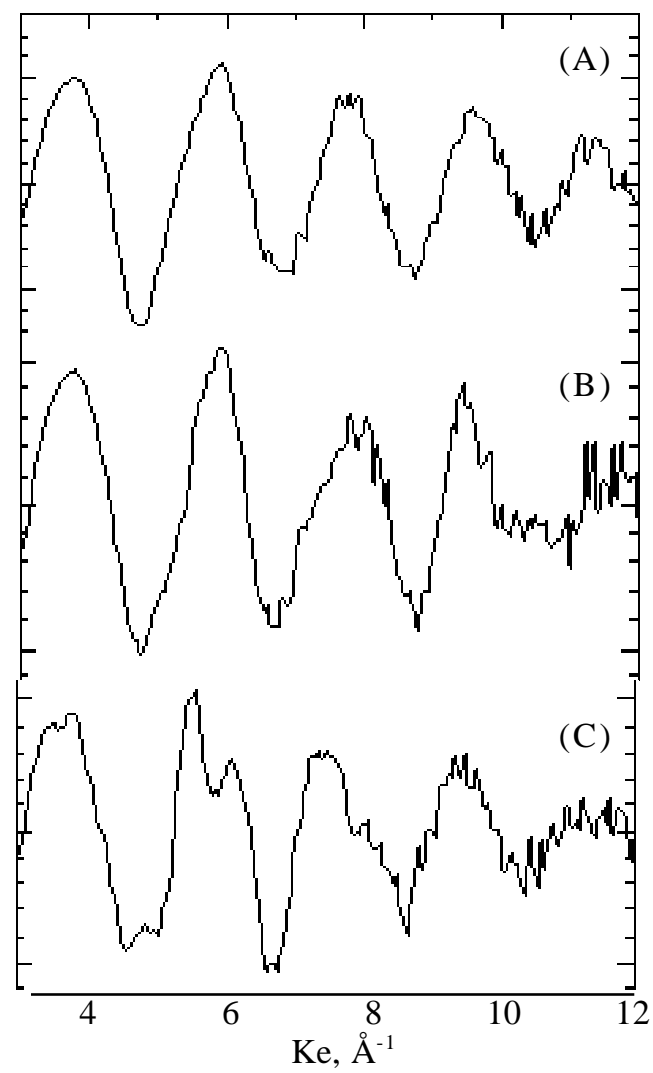

Figure 1. Ni EXAFS data of 100ppm aqueous Ni (A), $50 \mathrm{ppm}$ Ni sorbed on calcite at $\mathrm{pH}$ 7.75 (B), and 500 ppb Ni coprecipitated in calcite (C) (EXAFS are $\mathrm{K}^{3}$ weighted; relative amplitudes shown for $\mathbf{y}$-axes).

also agreed with $\mathrm{Ni}-\mathrm{Ni}$ distances in $\mathrm{Ni}(\mathrm{OH})_{2}$. Second neighbors in sorption samples were, therefore, dominated by $\mathrm{Ni}$ atoms. The coordination number for $\mathrm{Ni}$ neighbors varied between 0.4 and 1.7, increasing with level of loading. When $\sigma^{2}$ was held at 0.0064 (average for $\mathrm{Ni}(\mathrm{OH})_{2}$ sample), $\mathrm{Ni}$ coordination numbers varied between 0.6 and 1.6. The addition of a $\mathrm{Ca}$ shell in addition to a $\mathrm{Ni}$ shell improved the EXAFS fit significantly for all samples. Ni may, therefore, be found as a surface precipitate that coats the calcite surface. Since EXAFS data always represents the average coordination of an element, it is also possible that $\mathrm{Ni}$ was found in several coordination environments on the calcite surface. Some Ni atoms may have substituted for $\mathrm{Ca}$ near the calcite surface while another fraction was in a $\mathrm{Ni}(\mathrm{OH})_{2}$-like coordination. At short times $(\sim 10$ hours $)$, either $\mathrm{Ni}(\mathrm{OH})_{2}$-like multinuclear complexes or a mixture of $\mathrm{Ni}(\mathrm{OH})_{2}$ like and Ni-substituted calcite species most likely formed in the presence of calcite.

\section{Ni(II) Coprecipitation in Calcite}

Ni XAS data for several coprecipitation samples were examined. The XANES were the same at all precipitation rates and $\mathrm{pCO}_{2}$ but distinctly different from $\mathrm{Ni}(\mathrm{OH})_{2}$, aqueous $\mathrm{Ni}$, or sorbed $\mathrm{Ni}$. The EXAFS and FTs were also different. Due to the complexity of the EXAFS, data fits were heavily constrained. For coprecipitation samples, data fits were initially constrained by assuming that $\mathrm{Ni}$ resides in the $\mathrm{Ca}$ position of calcite such that coordination numbers of atoms were held constant. Atom distances, $\sigma^{2}$, and $\mathrm{S}_{0}{ }^{2}$ were fit. For coprecipitation samples, with the addition of each shell of atoms, the fit improved and the first and second shell oxygen $\sigma^{2}$ values agreed with $\mathrm{NiO}$ fit results. Not all atoms in the nearest $5 \AA$ from the $\mathrm{Ca}$ position were fit; 3 sets of 6 equivalent $\mathrm{O}$ atoms between 4 and $5 \AA$ were omitted to reduce the number of fitting parameters. Though the $\sigma^{2}$ for $\mathrm{O}$ at that distance was expected to be very high, a relatively poor fit between 3.5 and $4 \AA$ of the EXAFS FT could be attributed to those $\mathrm{O}$ atoms (Figure 2).

The coprecipitation data fits suggest that substitution of $\mathrm{Ca}$ for $\mathrm{Ni}$ in calcite results in the distortion of interatomic distances in the calcite lattice. The difference in atom distances (relative to ideal calcite) for the fitted atoms was $-0.27,-0.10$,

$-0.09,-0.11,-0.07 \AA$ for increasingly distant backscatterers (Figure 3). Thus, Ni substitution disturbed the atom lattice positions to at least $5 \AA$. Though significant distortion of the calcite lattice occurred, EXAFS results indicate $\mathrm{Ni}$ substituted directly for $\mathrm{Ca}$ in calcite.

Since the ionic radius of $\mathrm{Cu}$ (II) is close to $\mathrm{Ni}(\mathrm{II})$ (0.73 and $0.69 \AA$, respectively), EXAFS data was collected on coprecipitated $\mathrm{Cu}$ (II) and several standards. When coprecipitation data was fit using the same scheme as for $\mathrm{Ni}$, the decrease in atom distance relative to calcite were -0.33 , $0.20,-0.22,-0.11$, and $-0.06 \AA$ for increasingly distant neighbors. In the case of $\mathrm{Cu}$, distortion of the calcite lattice occurred similar to $\mathrm{Ni}$ and distortion beyond $5 \AA$ was detectable. However, poor data fits for the $\mathrm{Cu}$ data indicated that, for $\mathrm{Cu}$, symmetric distortion of the carbonate site most likely did not occur. Bond valence calculations indicated that octahedrally 
coordinated $\mathrm{O}$ atoms at $2.03 \AA$ (fit result) were significantly too short for divalent $\mathrm{Cu}$. This is likely due to the typical non-ideal octahedral coordination of $\mathrm{Cu}-\mathrm{O}$ species that have $4 \mathrm{O}$ at $\sim 1.9 \AA$ and 2 at $\sim 2.5 \AA$. Both $\mathrm{Ni}$ and Mn usually have equidistant octahedral coordination and atom distances for coprecipitation samples are in agreement with bond-valence calculations.
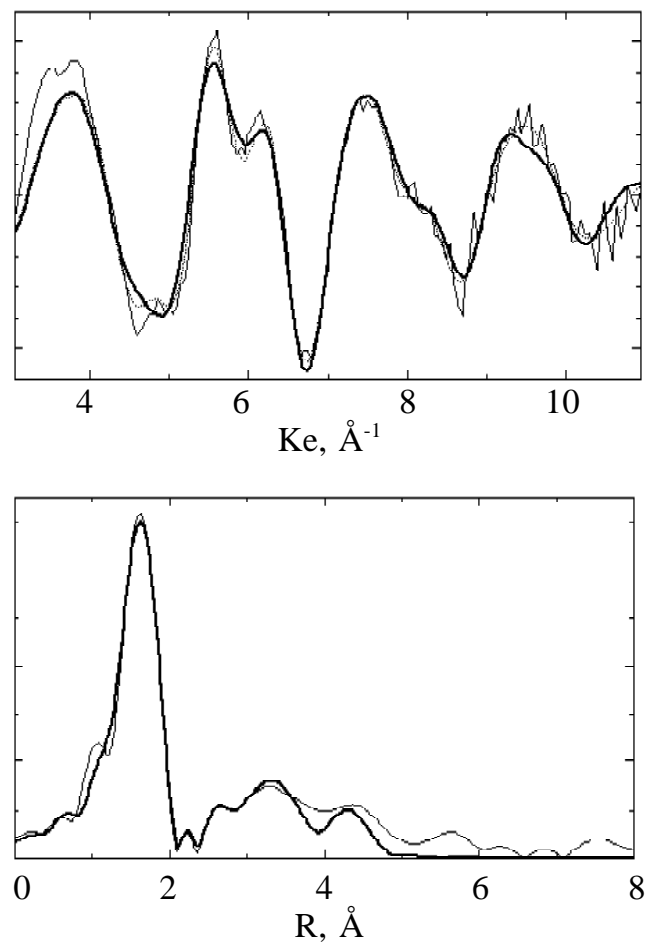

Figure 2. Data fit for $\mathrm{Ni}$ coprecipitation sample (solid line $=$ data, dotted line $=$ backtransform, thick line = back-transform fit; EXAFS and FT's are $\mathrm{K}^{3}$ weighted; relative amplitudes shown for all $\mathbf{y}$-axes).

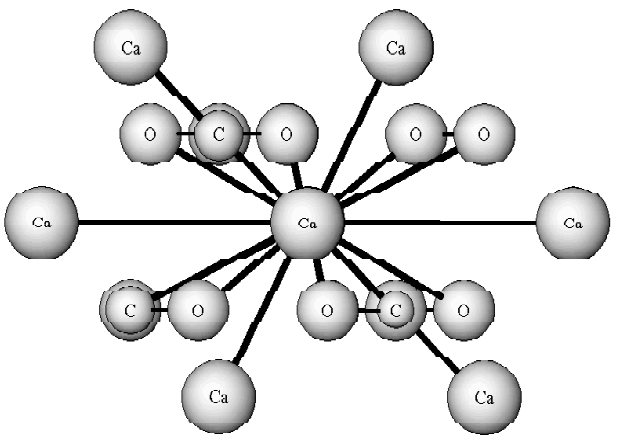

Figure 3. A diagram depicting the $\mathrm{O}, \mathrm{C}$, and $\mathrm{Ca}$ cluster of atoms that was fit in $\mathrm{Ni}$ coprecipitation EXAFS data.

\section{Mn(II) Sorption on Calcite}

For all sorption samples, Mn loading on calcite was low and EXAFS data fitting could not be accomplished. Though Mn sorbs more strongly to calcite than $\mathrm{Ni}$, the $\mathrm{Mn}$ detection limits were significantly higher. Nevertheless, XANES data indicated that sorbed $\mathrm{Mn}$ was not dominated by an aqueous or $\mathrm{MnCO}_{3}$-like species. $\mathrm{Mn}$ (II) sorption data was time-dependent during the period of XAS data collection. When examining the XANES as a function of time, the spectrum shape changed as a function of time (Figure 4). Each sorption scan is an average of several scans that represent approximately 2 hours of reaction time. For this sample, XAS data collection began after only a few hours of sorption. The first scan looks most like aqueous $\mathrm{Mn}(\mathrm{II})$ (or, possibly surface sorbed Mn(II)). The formation of additional XANES peaks as a function of time (and other EXAFS evidence) suggests a fast transformation from Mn sorption to solid solution formation (compare with $\mathrm{Mn}$ coprecipitation XANES).

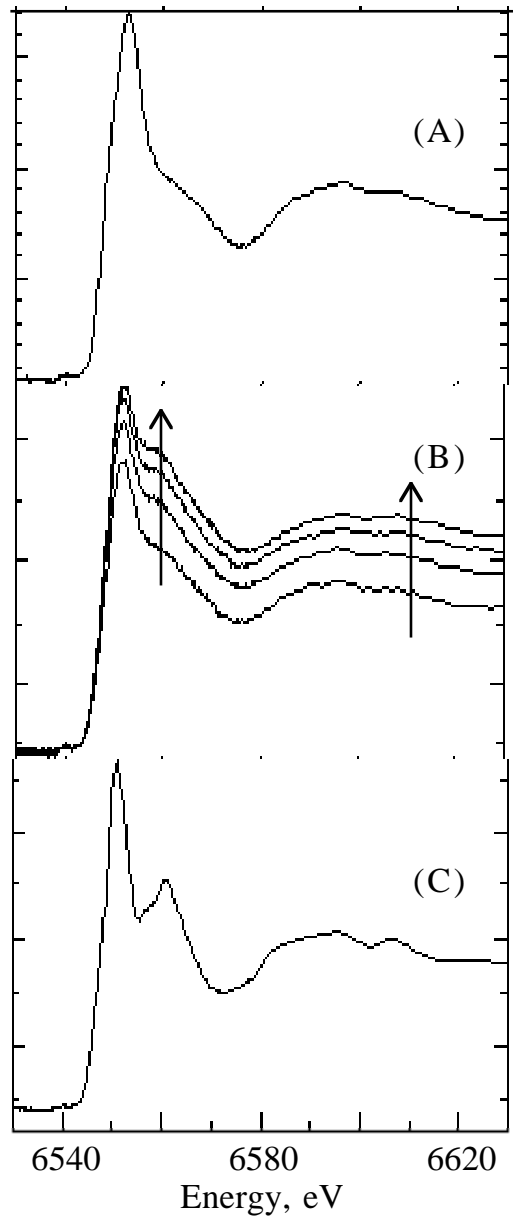

Figure 4. Mn XANES of $100 \mathrm{ppm}$ aqueous $\operatorname{Mn}(\mathrm{II})$ (A), Mn(II) sorbed on calcite at $\mathbf{p H}$ 7.75, $\mathrm{I}=0.1,0.03 \% \mathrm{CO}_{2}(\mathrm{~B})$, and $500 \mathrm{ppb}$ 
Mn(II) coprecipitated at $0.03 \% \quad \mathrm{CO}_{2}$ and $\Omega=$ 3 (C) (relative amplitudes shown on y-axes; arrows indicate time trend).

Additional Mn sorption data suggested that, unlike $\mathrm{Ni}$ that formed a stable $\mathrm{Ni}(\mathrm{OH})_{2}$ surface precipitate, $\mathrm{Mn}$ (II) interaction with calcite was a function of time and solution concentration. At low $\mathrm{Mn}$ (II) concentrations, $\mathrm{Mn}$ was found on calcite with a structure similar but not identical to Mn-substituted calcite; Mn was most likely substituting for $\mathrm{Ca}$ at the calcite surface or was quickly incorporated to form a solid solution in calcite. At higher $\mathrm{Mn}(\mathrm{II})$ concentrations, Mn formed a surface precipitate evidenced by $\mathrm{Mn}$ Mn back-scattering. Within several hours, $\mathrm{Mn}$ (II) began to form a solid solution in calcite via diffusion through the hydrated calcite layer or calcite recrystallization, finally forming a structure similar to $\mathrm{Mn}$ substituted calcite. These EXAFS results provide direct evidence for the model described by Davis et al. ${ }^{6}$ where sorption was described as a 2-step process of surface sorption followed by solid solution formation through surface recrystallization. The results also agree with $\mathrm{Mn}$ sorption observations of Zachara et al. ${ }^{4}$ that indicated irreversible $\mathrm{Mn}$ sorption on calcite; the irreversible nature of $\mathrm{Mn}$ (II) sorption was most likely due to incorporation beyond the surface of calcite. The difference in reactivity of $\mathrm{Ni}$ and $\mathrm{Mn}$ sorption can be related to the relative ease of $\mathrm{Mn}$ dehydration compared to $\mathrm{Ni}$ (i.e. Mn dehydrates and can then substitute for $\mathrm{Ca}$ in calcite while $\mathrm{Ni}$ remains largely at the surface $)^{4}$.

\section{Mn(II) Coprecipitation in Calcite}

Several Mn(II) coprecipitation samples were examined using XAS. Precipitation rate and $\mathrm{pCO}_{2}$ in the ranges examined did not affect the structure of $\mathrm{Mn}$ in calcite. The XANES contained 2 peaks near $6600 \mathrm{eV}$ similar to the XANES of Mn sorption samples (Figure 4). These XANES were also significantly different from $\mathrm{MnCO}_{3}$. The EXAFS FT data contained multiple features as in $\mathrm{Ni}$ and $\mathrm{Cu}$ coprecipitation results. The Mn coprecipitation EXAFS FTs were quite similar to $\mathrm{MnCO}_{3}$ data though conspicuously different. A comparison of EXAFS data led to the same conclusion: though many of the features in coprecipitated $\mathrm{Mn}$ and $\mathrm{MnCO}_{3}$ are similar, there are distinct difference between the spectra.

Data fits for coprecipitation samples showed similar changes in atoms distances as $\mathrm{Ni}$ and $\mathrm{Cu}$ coprecipitation results, though the effects were much slighter since $\mathrm{Mn}$ and $\mathrm{Ca}$ ionic radii are similar $(\mathrm{Mn}(\mathrm{II})=0.8 \AA$ and $\mathrm{Ca}(\mathrm{II})=1.0 \AA)$. Consequently, the distortion of fitted atoms distances relative to $\mathrm{Ca}$ positions in calcite were $-0.14,-0.03,-0.07,-0.05,+0.01$ for the nearest 5 fitted atom shells. In the case of $\mathrm{Mn}$ coprecipitation, distortion of calcite did not reach the second shell of $\mathrm{Ca}$ atoms and was slight beyond the first shell of $\mathrm{O}$ atoms. Although the fits assumed that no Mn was present in the first or second shell of divalent cation sites, this may not necessarily be the case. When fits were made with $\mathrm{Mn}$ instead of $\mathrm{Ca}$ back-scatterers, the fits were worse and fitted $\sigma^{2}$ values were too large. Nevertheless, a fraction of first or second shell divalent cation sites may contain some $\mathrm{Mn}$ atoms. This same argument could be made for Ni coprecipitation samples.

\section{References}

1. Doner, H. E. \& Zavarin, M. in Soils and Environment - Soil Processes from Mineral to Landscape Scale (eds. Auerswald, K., Stanjek, H. \& Bigham, J. M.) (Catena Verlag, 1996).

2. Dromgoole, E. L. \& Walter, L. M. Inhibition of calcite growth rates by $\mathrm{Mn}^{2+}$ in $\mathrm{CaCl}_{2}$ solution at 10, 25, and 50C. Geoch. et Cosmoch. Acta 5, 2991-3000 (1990).

3. Kopp, O. C., D.K. Reeves, M. L. Rivers, and J.V. Smith. Synchrotron X-ray fluorescence analysis of zoned carbonate gangue in Mississippi Valley-type deposits. Chemical Geology 81, 337-347 (1990).

4. Zachara, J. M., Cowan, C. E. \& Resch, C. T. Sorption of divalent metals on calcite. Geoch. et Cosmoch. Acta 55, 1549-1562 (1991).

5. Scheidegger, A. M., Lamble, G. M. \& Sparks, D. L. in Contaminated Soils: Third International Conference on the Biogeochemistry of Trace Elements (ed. Prost, R.) D:Idatalcommunicl011.PDF (INRA Editions, Paris, France, 1995).

6. Davis, J. A., Fuller, C. C. \& Cook, A. D. A model for trace metal sorption processes at the calcite surface; adsorption of $\mathrm{Cd}^{2+}$ and subsequent solid solution formation. Geoch. et Cosmoch. Acta 51, 1477-1490 (1987). 